\title{
Oferta Turística de Bertioga (SP): caracterização, evolução e análise
}

\author{
Tourism Supply in Bertioga (SP): \\ characterization, evolution and analysis
}

\section{Rafael Chequer Bauer \\ Mirian Rejowski}

\begin{abstract}
RESUMO: Estudo exploratório-descritivo sobre a oferta turística do município de Bertioga (São Paulo, Brasil). Apresenta considerações teóricas sobre oferta turística, síntese elucidativa do atual estágio de desenvolvimento de sua atividade turística, analisando aspectos quali-quantitativos de sua oferta turística. Conclui destacando a necessidade de planejamento responsável e gestão integrada do turismo municipal, e sugere algumas propostas para tanto.
\end{abstract}

PALAVRAS-CHAVE: oferta turística; equipamentos turísticos; diagnóstico; desenvolvimento sustentável; propostas; Bertioga; São Paulo; Brasil.

ABSTRACT: Descriptive-exploratory study about the tourist offer of the city of Bertioga (São Paulo, Brazil). It presents a clarifying synthesis of the present situation of the development of tourism in the city, focusing the qualitatives and quantitatives aspects of its tourist offer. It concludes with proposals about the responsible planning integrated management of tourism in the city.

KEYWORDS: tourist offer; tourist equipaments; diagnostic; sustainable tourist development; proposals; Bertioga; São Paulo; Brazil.

1. Bacharel em Turismo pela Escola de Comunicaçōes e Artes da Universidade de São Paulo (ECAUSP). E-mail: rafsyoda@hotmail.com

2. Bacharel em Turismo, Mestre e Doutora em Ciências da Comunicação pela Escola de Comunicações e Artes da Universidade de São Paulo (ECA-USP). Livre-Docente em Teoria do Turismo e do Lazer pela ECA-USP. Professora do Mestrado em Turismo da Universidade de Caxias do Sul e do Mestrado e Doutorado em Ciências da Comunicação/ Turismo e Lazer da ECA/USP. E-mail: mirwski@usp.br 


\section{Introdução}

Bertioga, importante estância balneária do Estado de São Paulo, é um município de inegável potencial turístico, mas que apresenta uma série de deficiências no que concerne ao desenvolvimento racional de seus recursos e equipamentos turísticos. Localiza-se no litoral do Estado de São Paulo, na região administrativa da Baixada Santista, da qual fazem parte outros oito municípios: Cubatão, Guarujá, Itanhaém, Mongaguá, Peruíbe, Praia Grande, Santos e São Vicente 3 . Bertioga é o município mais setentrional dessa região, fazendo limite com o chamado Litoral Norte, do qual fazem parte os municípios de Caraguatatuba, Ilha Bela, São Sebastiāo e Ubatuba.

Assim, pode-se afirmar que Bertioga situa-se no trecho transitório entre a Baixada Santista e o Litoral Norte, por possuir características que remontam às duas regiōes. Um exemplo desse caráter ambivalente aponta que o município pode ser considerado como uma extensão da parte mais austral do município de São Sebastiāo, com quem faz fronteira ao Norte, pois possui também uma ampla faixa litorânea extremamente plana, coberta por vegetação de restinga. Por outro lado, Bertioga se assemelha a Santos, no que concerne à hidrografia, por possuir vários cursos d'água em seu relevo, tais como o Rio Itapanhaú, o Canal de Bertioga, o Rio Itaguaré e o Rio Guaratuba, que deságuam diretamente no Oceano Atlântico e que permitem a presença de grande extensão de vegetação de manguezais. Seu clima é considerado tropical chuvoso, caracterizado por verões quentes e úmidos e invernos amenos e com precipitaçōes chuvosas brandas (Ribeiro, 1999).

Mais da metade de seu território é ocupado pelo Parque Estadual da Serra do Mar, sendo o município com a maior área verde de proteção ambiental em todo o Estado de São Paulo4. Sua área urbana está comprimida entre a Serra do Mar e o Oceano Atlântico, num dos trechos paulistas de maior proximidade entre a Mata Atlântica e a costa.

Estimava-se em 2001 que sua população fixa era de 30.903 habitantes, apresentando uma das maiores taxas de crescimento populacional anual do País: $16,11 \%$. Esta taxa pode ser explicada pela recente expansão imobiliária observada nas cercanias de sua orla marítima, que absorve uma intensa mão-de-obra, aliada à migração.

3. Tàis municípios foram englobados nessa divisão regional por possuírem características fisiográficas e de ocupação do solo semelhantes.

4. Conforme www.com.br/guiadolitoral.
Outro índice estatístico importante diz respeito à distribuição domiciliar do município: $66,2 \%$ dos domicílios são considerados desocupados; no entanto, $90 \%$ destes têm uso esporádico, ou seja, 15.691 dos 26.149 (60\% do total) são usados como segunda residência (IBGE, 2000).

Este artigo é parte de uma pesquisa exploratório-descritiva sobre a evolução do turismo e o diagnóstico da oferta turística de Bertioga desenvolvida no período de agosto de 2000 a dezembro de 2001, como projeto de iniciação científica, a qual foi apoiada pela Fapesp - Fundaçāo para o Amparo da Pesquisa no Estado de São Paulo. Teve por objetivo principal enfocar a oferta técnica do município, com destaque para seus equipamentos principais, identificando-a, caracterizando-a e analisando-a sob o ponto de vista quali-quantitativo. Para tanto, baseou-se em revisão bibliográfica sobre a oferta turística, ressaltando os equipamentos e serviços, e estudos sobre o turismo em municípios litorâneos do Estado de São Paulo; elaboração de cadastro de equipamentos turísticos; observação e coleta de dados, mediante visita "in loco" em cada equipamento cadastrado, com registro em fichas técnicas; entrevistas com proprietários e/ou responsáveis pelos equipamentos e reuniōes com representantes da Prefeitura Municipal.

Apresenta-se, a seguir, uma síntese parcial dos resultados desse estudo, abordando o desenvolvimento do turismo no município, com base na caracterização, evolução e análise da sua oferta turística.

\section{Oferta Turística - aspectos conceituais}

É importante salientar que o termo oferta turística vem sendo, com freqüência, objeto de estudo e pesquisa na área de Turismo, tanto na literatura internacional quanto na nacional. Desta forma, o presente artigo baseia-se no pensamento de alguns dos principais estudiosos do assunto, para, a partir de então, descrever e analisar os dados coletados no estudo de caso realizado em Bertioga.

Segundo Baptista (1990), a oferta turística é constituída por todos os elementos que contribuem para a satisfação das necessidades de ordem psíquica, física e cultural que estão na origem das motivaçōes dos turistas. A critério do mesmo, existe normalmente a tendência para confundir a oferta turística com as instalações de alojamento e alimentação, associadas a um fator específico de atração, tanto na cidade como na praia e/ou campo.

Ruschmann (1997), por sua vez, afirma que a oferta turística de uma localidade é constituída da soma de todos os produtos e bens adquiridos ou consumidos pelo turista durante sua estada em uma destinação. Algo muito próximo do 
que define a própria Organização Mundial do Turismo: "conjunto de produtos turísticos e serviços postos à disposição do usuário turístico num determinado destino, para seu desfrute e consumo" (OMT: 1998).

Já Beni (2000), tratando do Sistur - Sistema de Turismo, afirma que oferta turística é um dos componentes do mercado turístico, que agrega os atrativos naturais e artificiais, os equipamentos e serviços específicos, e a infra-estrutura básica de apoio (vias de acesso e transportes, saneamento básico, etc). Segundo esse autor, o chamado produto turístico é formado pela soma entre a oferta primária ou original (atrativos turísticos: naturais, culturais e artificiais) e a oferta agregada ou derivada (serviços: transportes, agências de viagem, operadoras turísticas, meios de hospedagem, equipamentos de recreação, alimentação e promoção). É preciso esclarecer que ao falar em oferta turística derivada, isto sugere que sua criação se deu após a primeira, o que nem sempre ocorre.

Ainda segundo Beni (2000), a oferta turística faz parte do conjunto de ações operacionais do Sistur, inserida dentro do subsistema de produção, e relacionando-se obviamente à demanda turística. Ao mesmo tempo em que sofre influências, é capaz de interferir nos subsistemas externos ao mercado turístico - conjunto da organização estrutural e conjunto das relações ambientais.

Complementando, Renoux (1972) considera a oferta como aspecto determinante da demanda turística, que em conjunto com a mesma compõe o mercado turístico. Afirma, ainda, que ela é formada por elementos tangíveis e intangíveis, e não por um único produto específico.

Quanto à sua caracterização, autores como Beni (2000) indicam como premissa o deslocamento da demanda para o "consumo" do produto, o que a diferencia das outras atividades econômicas, em que a produção e o consumo podem ocorrer no mesmo tempo e espaço. Outra característica marcante da oferta turística é a sua heterogeneidade, uma vez que se constitui da justaposição de bens e serviços oferecidos aos turistas e consumidos por eles, tal como afirma Ruschmann (1997) ao agrupá-los em duas categorias de oferta:

- As atrações que são os recursos naturais, socioculturais e tecnológicos, também chamados de oferta diferencial, porque da sua diversidade depende o seu grau de atratividade. Mercadologicamente, são responsáveis pela escolha do turista por uma destinação em detrimento da outra.

- Os equipamentos e serviços (ou "facilidades"), que correspondem aos alojamentos, serviços de alimentação, de entretenimentos, de transporte para a localidade e dentro dela, responsáveis pelo maior ou menor tempo de permanência do turista, de acordo com sua qualidade e preço.
Também são chamados de elementos da oferta técnica, considerada específica, quando se relaciona aos serviços eminentemente turísticos, e geral, quando seus componentes atendem a população como um todo e correspondem aos equipamentos da infra-estrutura local.

$\mathrm{Na}$ realidade, a complexidade e a diversidade das razões que motivam o desejo de viagem exige uma análise mais aprofundada desse tema. A oferta diferencial (clima, paisagem, patrimônio histórico e cultural, tradições, folclore, artesanato, etc.) deve constituir o argumento base à definição de uma política de turismo e à concepção da natureza da oferta técnica a ser desenvolvida (hotéis, restaurantes, equipamentos de recreação, etc.).

Nesse sentido, deve-se levar em consideração as características e a qualidade da infra-estrutura existente ou a criar (saneamento básico, saúde, transportes, comunicações, etc.), depois de serem identificados e caracterizados os segmentos de mercado e captados os tipos de serviço a serem disponibilizados. Ao agregar as necessidades dos turistas aos aspectos que compõem a oferta turística de uma localidade, tem-se a perspectiva de sucesso e satisfação às partes envolvidas, envolvendo, portanto, o próprio turista, os órgãos gestores, os empreendedores turísticos, a comunidade e o próprio ambiente onde se desenvolve a atividade.

\section{Turismo em Bertioga - estudo de caso da oferta turística}

\section{Evolução do Turismo}

O desenvolvimento da oferta turística e da própria atividade turística em Bertioga deu-se a partir de meados do século XX, graças a dois aspectos principais: a melhoria do acesso ao município (com o asfaltamento da Rodovia MogiBertioga) e o início da saturação turística e imobiliária de balneários próximos, como Santos e Guarujá.

Até 1950, Bertioga constituía-se praticamente como uma vila de pescadores, apesar de seu passado valioso, marcado pela importância estratégica de defesa do litoral paulista e brasileiro (séculos XVI e XVII), extração comercial de óleo de baleia (século XVIII) e do fornecimento de energia elétrica à Baixada Santista no final do século XIX e início do século XX (através da Usina de Itatinga). Graças à construção da Colônia do Sesc - Serviço Social do Comércio - em 1948 e a concomitante inauguração do 27 Praia Hotel, inicia-se um período de expansão do turismo praticamente ininterrupto até os dias atuais, mas com fases distintas. 
Entre as décadas de 1950 e 1970 o então distrito de Bertioga, pertencente a Santos, surgira no cenário paulista como um destino sofisticado e de acesso restrito. A consolidação dos equipamentos turísticos da época traziam a este "longínquo" e ainda rústico balneário um público elitista e disposto a conhecer novos produtos turísticos.

Com a conclusão da Rodovia Manoel Hipólito Rego (Rio-Santos) na década de 1970, o fluxo turístico aos balneários paulistas se expande em direção ao Litoral Norte. Como a rodovia atravessa o município em sua porção periférica, a demanda sofre uma mudança de perfil, aparecendo durante as décadas de $1970 \mathrm{e}$ 1980 um público considerado "naturalista", acompanhado de um crescente fluxo de turistas de classe média, devido em parte à saturação de destinos mais famosos da Baixada Santista.

Por fim, a última fase constatada no desenvolvimento turístico dá-se a partir de sua emancipação em relação a Santos, em 1991, somada à conclusão da Rodovia Mogi-Bertioga, alterando novamente o perfil de sua demanda turística. Tem-se, a partir de então, a consolidação de uma demanda mais abrangente, contando com a presença de veranistas tradicionais (normalmente confinados em condomínios) e a expansão do número de excursionistas, de caráter mais popular. Além disso, a potencialidade turística do município é melhor utilizada com o incremento espontâneo de segmentos como o turismo náutico, de pesca e ecológico.

O município pode ser considerado privilegiado no que tange à sua oferta natural. Possui uma vasta reserva nativa, praticamente intocada e protegida por lei, com uma biodiversidade e beleza cênica ímpares. Além disso, boa parte do trecho de Mata Atlântica pertencente ao município encontra-se incrustada no Parque Estadual da Serra do Mar muito próximo da costa, o que torna Bertioga um destino único, por propiciar uma oferta conjunta de florestas e praias próxima aos municípios da Grande São Paulo.

Entre alguns dos principais exemplos dessa oferta tem-se o mangue, as matas ciliar, de restinga e de encosta, os Rios Jaguareguava, Itaguaré, Itapanhaú, as praias Branca e Itaguaré, além das inúmeras cachoeiras, trilhas, montanhas e da própria fauna, flora e paisagens da região. Dentre os atrativos turísticos naturais do município, destacam-se os 33 quilômetros de praias, as inúmeras trilhas e a pesca.

Como oferta histórico-cultural, o destaque é sem dúvida o Forte São João, considerado o mais antigo do Brasil (construído em 1547). Outros exemplos de realce do seu patrimônio histórico são a Estação Ferroviária e a Vila de Itatinga,

5. Isto explica a expansão de equipamentos de hospedagem voltados à natureza, como os campings. ambas com arquitetura do início do século XX, de influência britânica, além das ruínas da capela da Fazenda Pelais (século XVII) e o Píer Religioso, de estilo singular, ao lado da Balsa.

Atualmente soma-se ainda a essa oferta a Praça XV de Novembro e a Aldeia Indígena do Rio Silveira, além de eventos, como o Réveillon e o Carnaval, e festas populares, como a Festa de Aniversário da Emancipação Municipal (maio), a Festa da Tainha (junho) e a Festa do Camarão na Moranga (agosto).

Com relação à oferta técnica, ou de equipamentos turísticos, pode-se inicialmente dizer que é extensa, abrangente e de crescimento contínuo, razoavelmente proporcional ao aumento da demanda e seus diferentes segmentos, como detalha-se no item a seguir.

\section{Equipamentos turísticos}

Entre os 144 estabelecimentos turísticos pesquisados (Tabela 1), detecta-se uma oferta composta em sua maioria por meios de alimentação $(56,3 \%)$ e de hospedagem $(36,1 \%)$, sendo estes subdivididos em três categorias (hotéis, pousadas e campings). Os equipamentos voltados ao entretenimento e recreação incluem espaços culturais, livrarias, cinemas, locadoras de vídeos, fliperamas, clubes e colônias de férias ${ }^{6}$. E, por fim, os relacionados ao agenciamento turístico envolvem agências de turismo.

Tabela 1 Equipamentos turísticos de Bertioga - 2001.

\begin{tabular}{lcr}
\hline \multicolumn{1}{c}{ Tipologia } & \multicolumn{2}{c}{ Freqüềncia } \\
\hline Meios de Hospedagem & $\mathrm{n}^{\circ}$ & $\%$ \\
• Hotéis & 52 & 36,1 \\
• Pousadas & 14 & 9,7 \\
• Campings & 33 & 22,9 \\
Bares, Restaurantes e Similares & 05 & 3,5 \\
Entretenimento e Recreação & 81 & 56,3 \\
Agência de Turismo & 10 & 6,9 \\
\hline TOTAL & 01 & 0,5 \\
\hline
\end{tabular}

6. Optou-se por considerar a colônia de férias na categoria de equipamento de entretenimento e recreação, pois, apesar de serem também meios de hospedagem, funcionam como verdadeiros clubes com associados voltados ao entretenimento e ao lazer. 
Interpretando a evolução cronológica da implantação dos equipamentos turísticos de Bertioga (Figura 1), nota-se uma tendência de crescimento do número de equipamentos e estabelecimentos voltados ao turismo a partir de 1994, confirmando que a maioria de seus estabelecimentos turísticos foi inaugurada após a emancipação política do município, acompanhando o crescimento da demanda constatado na última década.

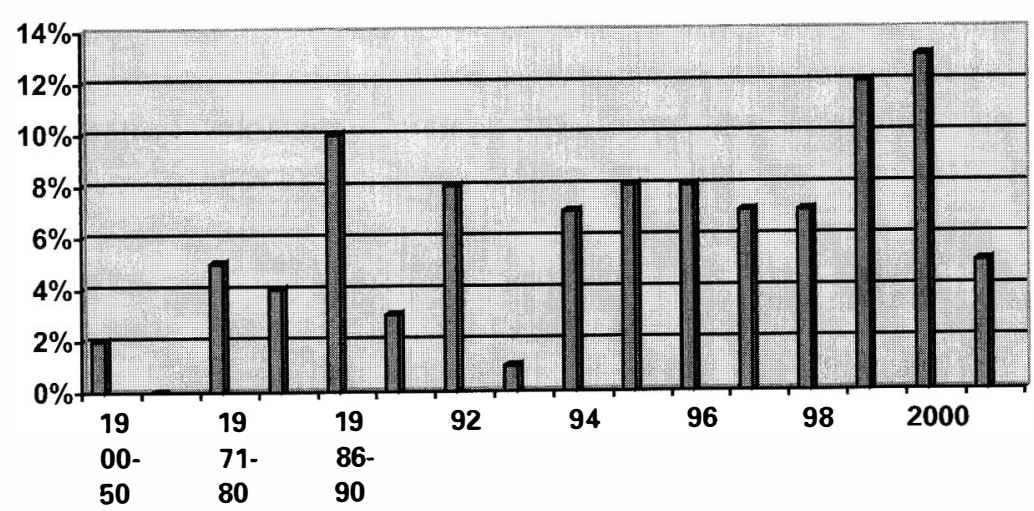

Figura 1 Evolução cronológica dos equipamentos turísticos.

Os resultados indicam que os hotéis apresentam uma condição em geral muito boa, visto que a maioria desses equipamentos apresenta uma boa oferta de serviços e equipamentos, além de uma estrutura de boa qualidade. A sua quantidade parece compatível com a demanda de turistas que freqüentavam a cidade no período da pesquisa. As taxas de ocupação média variam de $86,4 \%$ na alta temporada e $27,3 \%$ na baixa temporada, sendo que nos hotéis de lazer e flats apresentam menor sazonalidade. O primeiro hotel surgiu em 1950, portanto, logo após a Segunda Guerra Mundial, e o primeiro flat em 1986. Mas seu maior crescimento ocorre na década de 1990, confirmando, assim, a expansão do turismo a partir da emancipação do município.

Constatou-se que o número de unidades habitacionais dos hotéis varia de 100 a 9, com uma média de 29 por hotel, não se configurando, portanto, a existência de grandes complexos hoteleiros - na verdade, muitos hotéis têm um porte similar ao das pousadas. O preço das diárias constitui outro aspecto positivo, pois propiciam um custo-benefício satisfatório aos hóspedes. Afinal, não se gasta muito, se comparado com outras estâncias balneárias da região, e usufrui-se de equipamentos e serviços compatíveis ao valor pago.
Os resultados apontam boa qualidade na oferta de hotéis, especialmente de hotéis de lazer e de flats situados no Condomínio Riviera de São Lourenço.

Em relação às pousadas, a principal constatação foi a de que a quantidade de estabelecimentos pesquisados (33) não corresponde à totalidade de meios de hospedagem desse tipo, uma vez que há várias pensões e pensionatos, em geral adaptação de residências, abertos informalmente na alta temporada (dezembro a fevereiro). Em 1971 e 1980 surgem as duas primeiras pousadas, tendo seu crescimento acentuado também a partir da década de 1990 . Cerca de $27 \%$ desses estabelecimentos surgiram a partir de 1999, podendo sugerir sua continuidade de crescimento em atender uma demanda de menor poder aquisitivo.

As unidades habitacionais (UH) das pousadas são, em média, preparadas para receberem uma família, visto que a média é de aproximadamente quatro leitos por UH. As taxas médias de ocupação variam de $87,7 \%$ na alta temporada a 29,5 na baixa temporada, um pouco acima das apresentadas pelos hotéis. Os preços são relativamente baixos, especialmente na baixa temporada. É importante frisar, ainda, a discrepância entre os estabelecimentos visitados, parte oferecendo bons serviços e equipamentos e parte qualidade regular e insatisfatória.

Também no caso dos campings, nem todos foram pesquisados pela falta de informações confiáveis sobre sua localização. No entanto, os de maior apelo turístico e oficialmente cadastrados tiveram seus dados descritos e analisados (5). As taxas de ocupação variam de $84 \%$ na alta temporada a $26 \%$ na baixa temporada, pouco abaixo dos hotéis e das pousadas. Sua infra-estrutura de serviços é razoável a boa, e é interessante notar, ainda, que todos os equipamentos pesquisados há mais de 15 anos, e $80 \%$ particularmente entre 1975 e 1984, não acompanharam a tendência de expansão observada nas pousadas.

O segmento de alimentação é o mais diversificado de toda a oferta técnica pesquisada. Em muitos aspectos foi o mais difícil de ser pesquisado, e optou-se por selecionar os de maior procura pelos turistas. São 81 estabelecimentos classificados em bares (subdivididos em bar convencional, bar e danceteria, "sushi bar" e "videokê bar"), restaurantes, lanchonetes, sorveterias, pastelarias e cafeterias. Mais da metade (56\%) são classificados como restaurantes, e seu crescimento acentuado também ocorre a partir de 1990. Trinta e nove por cento surgiram também a partir de 1999, provavelmente acompanhando o crescimento populacional do município e os períodos de fluxo turístico mais intenso.

Esses equipamentos atendem tanto o turista (67\%) quanto o residente (33\%), daí suas taxas médias de ocupação serem mais altas do que outros equipamentos pesquisados - na alta temporada é de $86,2 \%$ e de $31,5 \%$ na baixa temporada. 
Muitas das colônias de férias também não foram pesquisadas pela dificuldade em localizá-las, por falta de dados anteriores e período exíguo de tempo para coleta de dados. Dentre essas, destaca-se a colônia de férias do Sesc - Serviço Social do Comércio, construída em 1948 como o primeiro equipamento turístico de Bertioga. De todos os equipamentos pesquisados (144) foi o melhor avaliado, contando com uma estrutura excelente e serviços reconhecidos há mais de meio século, e com grande contingente de funcionários (295).

Entre as agências de turismo, apenas uma foi pesquisada, apesar da suposta existência de mais duas, as quais talvez funcionem somente na alta temporada. A agência pesquisada foi fundada em 1996 e caracteriza-se como agência de turismo nacional, de pequeno porte. Destaca-se pela satisfatória qualidade de serviços, especialmente aqueles voltados ao turismo receptivo de cunho ecológico.

\section{Diagnóstico}

Bertioga, como muitos municípios potencialmente turísticos do País, tem encontrado dificuldades na utilização racional de seus recursos turísticos. A trajetória política, econômica, sociocultural, ambiental da localidade e do próprio País são premissas fundamentais à compreensão e execução do incremento sustentável da atividade turística, o que torna o conjunto de açōes necessário para seu desenvolvimento racional um compromisso multissetorial e integrado.

Desta forma, antes de diagnosticar o atual estágio de desenvolvimento turístico do município e da utilização de sua oferta turística, é preciso ratificar a condição macroestrutural comum à boa parte dos municípios brasileiros. Bertioga também apresenta problemas estruturais graves, como desigualdade social acentuada, dificuldades econômicas, falta de infra-estrutura urbana e entraves políticos. Deste modo, a atividade turística também é afetada, pois em se tratando de uma vertente de desenvolvimento socioeconômico, está à mercê das intempéries políticas, econômicas e sociais do País.

Entretanto, a situação macroestrutural específica de Bertioga apresenta algumas peculiaridades, o que permite traçar um perfil particularizado do município, em relação aos demais municípios do litoral paulista e brasileiro.

A primeiradelasé sua atual condição política. Emancipado em 1991, o município começa a se estruturar politicamente, buscando concentrar da melhor forma os recursos em prol da localidade. Antes, constituía-se como um distrito de Santos, o que impossibilitou um desenvolvimento socioeconômico mais dinâmico.
Como os demais balneários do País, possui uma dependência grande em relação à atividade turística, e, por conseguinte, é afetada por sua sazonalidade. Bertioga é um município com desigualdades sociais maiores que boa parte dos municípios litorâneos de São Paulo. O grande número de condomínios de luxo contrasta com a profusão de favelas, oriunda especialmente da desqualificação profissional da população, um problema relacionado à construção desses grandes empreendimentos imobiliários, que atraíram uma mão-de-obra migrante desqualificada.

Geograficamente está numa posição privilegiada, situando-se próximo da Região Metropolitana de São Paulo (pólo emissor), possuindo fácil acesso, além de interligar-se com os municípios da Baixada Santista e do Litoral Norte Paulista, funcionando como zona de transição entre as duas regiōes.

Sua condição ambiental também é bastante favorável, uma vez que possui uma biodiversidade exuberante, sendo boa parte ainda imune à ação predatória do ser humano. Além disso, é o único município da Baixada Santista que agrega de forma próxima e em grande escala a oferta de praias e de Mata Atlântica nativa.

Seu patrimônio histórico-cultural é um dos mais ricos do Litoral Paulista, apresentando, porém, má conservação de alguns bens históricos e lentidão nos processo de preservação e utilização sustentável dos mesmos. Sua herança cultural indígena começou a ser valorizada recentemente, após anos de descaso.

Bertioga apresenta uma atividade turística que permanece, ao lado da construção civil e da pesca, como principal atividade econômica do município. A popularização do fenômeno turístico na região é notória, já que o município recebe uma quantidade crescente de excursionistas (pessoas que permanecem menos de 24 horas no local visitado, sem pernoitar no mesmo e, portanto, não sendo considerados turistas), além dos próprios residentes temporários (chamados também de veranistas, os quais normalmente possuem segundas residências no município visitado, utilizando-as essencialmente durante o verão). Atualmente, o perfil do visitante de Bertioga é um turista de renda média, que reside em um raio de 150 quilômetros, oriundo principalmente da Região Metropolitana da cidade de São Paulo, o qual freqüenta o município durante os meses de férias escolares.

Comparando-se com os demais municípios do Litoral Paulista, Bertioga apresenta como grande "trunfo" de apelo turístico uma combinação de patrimônio natural e cultural diferenciada. Sua oferta técnica não deixa a desejar, em relação à maioria dos municípios paulistas banhados pelo mar.

Identifica-se na oferta de equipamentos turísticos pesquisada uma grande diversidade quali-quantitativa. Suas características variam de acordo com a tipologia, sendo que os diferentes segmentos analisados apresentam, sem exceção, uma 
maioria de estabelecimentos com condições razoáveis à recepção de turistas. Portanto, ao lado dessa oferta técnica já instalada, agrega-se uma oferta primária a ser melhor "trabalhada", justamente para atrair uma diversidade maior de demanda, mais qualificada.

A vocação turística do município assenta-se no turismo litorâneo, ao lado de outras potencialidades ainda pouco exploradas como o ecoturismo, o turismo náutico e de pesca, o turismo cultural, o turismo de eventos e o turismo científico.

\section{Considerações Finais}

A exploração do turismo em Bertioga, a partir deste breve estudo de sua oferta, em especial de atrativos e equipamentos turísticos, considerando ainda outros componentes do sistema de turismo, mostra a importância da pesquisa continuada para nortear as ações de planejamento e gestão municipal na área. A utilização de recursos e atrativos turísticos de um destino turístico pode ser incrementada com estudos mais aprofundados dos vários segmentos do turismo e sua correlação com outros setores, como educação, saúde, segurança, transporte, meio ambiente, etc. tanto sob o âmbito macro quanto microestruturais.

Ressalta-se, desta forma, a necessidade da implementação coerente e eficiente de gestão integrada, a partir de um planejamento ao mesmo tempo específico de cada segmento, mas que acompanhe a evolução genérica do município. Faz parte desse processo a implantação de um projeto de desenvolvimento turístico sustentável, incluindo o planejamento integrado e responsável ao lado da gestão compartilhada.

\section{Referências Bibliografias}

ANDRADE, José V. de. 1992. Turismo: fundamentos e dimensōes. São Paulo: Ática.

AZEVEDO, Aroldo de. 1996. A Baixada Santista: aspectos geográficos. Faculdade de Filosofia, Ciências e Letras da Universidade de São Paulo, Departamento de Geografia, v.1, 2, 3 e 4.

BAPTISTA, Mário M. 1990. O turismo na economia: uma abordagem técnica, econômica, social e cultural. Lisboa: Instituto Nacional de Formação Turística.

BAUER, Rafael C. 2001. Evolução e diagnóstico da oferta turística de Bertioga. São Paulo: Trabalho de Conclusão de Curso de graduação em Turismo; Escola de Comunicaçōes e Artes da Universidade de São Paulo (ECA-USP).

BENI, Mário C. 2000. Análise estrutural do turismo. 3 ed. São Paulo: Senac.
GUIA BRASIL 4 RODAS. 2000. São Paulo: Abril.

IBGE. 2000. Censo do Instituto Brasileiro de Geografia e Estatística.

IGNARRA, Luís. 1999. Fundamentos do turismo. São Paulo: Pioneira.

RENOUX, M. 1972. L'économie du tourisme. Paris: Éditions du Seuil.

RIBEIRO, Roberto. 1999. Diagnóstico de saúde do município de Bertioga. Santos: Fiscal da Vigilância Sanitária de Bertioga e de Santos.

RUSCHMANN, Dóris V. 1997. Marketing turístico. Campinas: Papirus.

Recebido em 18/02/2002

Aprovado em 10/04/2002 